\section{Cureus}

Received 09/06/2016

Review began 09/12/2016

Review ended 10/01/2016

Published 10/07/2016

\section{(C) Copyright 2016}

Vaishya et al. This is an open access article distributed under the terms of the Creative Commons Attribution License CC-BY 3.0., which permits unrestricted use, distribution, and reproduction in any medium, provided the original author and source are credited.

\title{
Haglund's Syndrome: A Commonly Seen Mysterious Condition
}

\author{
Raju Vaishya ${ }^{1}$, Amit Kumar Agarwal ${ }^{1}$, Ahmad Tariq Azizi ${ }^{2}$, Vipul Vijay ${ }^{1}$ \\ 1. Department of Orthopedics, Indraprastha Apollo Hospital, New Delhi 2. Orthopaedics, Herat Regional \\ Hospital, Herat, Afghanistan
}

$\square$ Corresponding author: Amit Kumar Agarwal, amitorthopgi@yahoo.co.in Disclosures can be found in Additional Information at the end of the article

\section{Abstract}

Haglund's deformity was first described by Patrick Haglund in 1927. It is also known as retrocalcaneal exostosis, Mulholland deformity, and 'pump bump.' It is a very common clinical condition, but still poorly understood. Haglund's deformity is an abnormality of the bone and soft tissues in the foot. An enlargement of the bony section of the heel (where the Achilles tendon is inserted) triggers this condition. The soft tissue near the back of the heel can become irritated when the large, bony lump rubs against rigid shoes. The aetiology is not well known, but some probable causes like a tight Achilles tendon, a high arch of the foot, and heredity have been suggested as causes. Middle age is the most common age of affection, females are more affected than males, and the occurence is often bilateral. A clinical feature of this condition is pain in the back of the heel, which is more after rest. Clinical evaluation and lateral radiographs of the ankle are mostly enough to make a diagnosis of Haglund's syndrome. Haglund's syndrome is often treated conservatively by altering the heel height in shoe wear, orthosis, physiotherapy, and anti-inflammatory drugs. Surgical excision of the bony exostoses of the calcaneum is only required in resistant cases.

Categories: Orthopedics

Keywords: haglund's syndrome, retrocalaneal exostosis

\section{Introduction And Background}

Haglund's deformity was first described by Patrick Haglund in 1927 [1]. It is also known as retrocalcaneal exostosis, Mulholland deformity, and 'pump bump.' Although a very common clinical condition, it is still poorly understood. It has no definitive etiology, but various probable causes like a tight Achilles tendon, a high arch of the foot, and heredity have been proposed. It usually affects middle-aged people, females more than males, and it is often bilateral. It is characterized by pain in the back of the heel, which is more after rest. Clinical evaluation and lateral radiographs of the ankle are mostly enough to make a diagnosis of Haglund's syndrome. The pain could be due to associated Achilles tendonitis and retrocalcaneal bursitis [2]. This condition can mimic other causes of hind foot pain like isolated retrocalcaneal bursitis, plantar fasciitis, and seronegative spondyloarthropathies [3].

Haglund's syndrome is often treated conservatively by altering the heel height in shoe wear, orthosis, physiotherapy, anti-inflammatory drugs, and local steroid injection. Surgical excision of the bony exostoses of the calcaneum is only required in resistant cases.

\section{Review}




\section{Cureus}

Haglund's deformity is an abnormality of the posterosuperior part of the calcaneus, where there is a bony enlargement at the attachment of the Achilles tendon. The adjoining soft tissues can get irritated when this bony lump rubs against rigid shoes. It often leads to retrocalcaneal bursitis, calcaneal tendon bursitis, and thickening and inflammation of the calcaneal tendon. This combination of pathology is known as Haglund's syndrome. Inflammation of the different parts of soft tissue in the area can lead to an isolated condition; however, the treatment options are different in these conditions, and so they should be differentiated.

\section{Cause}

It is mostly an idiopathic condition, but several contributory factors like over-practice in runners, tight or poorly fitting shoes, or altered biomechanics of foot joints because of the dealigned subtalar joint may play a role [4].

\section{History}

Pain at the posterior heel is the presenting feature. It may be associated with limping and swelling. The pain is prominent while the patient begins to walk after rest. This condition may be unilateral or bilateral. History of any rheumatologic conditions like gout, rheumatoid arthritis, or seronegative spondyloarthropathies should be considered. [5].

\section{Physical examination}

A bump is seen on the posterior heel (Figure 1).

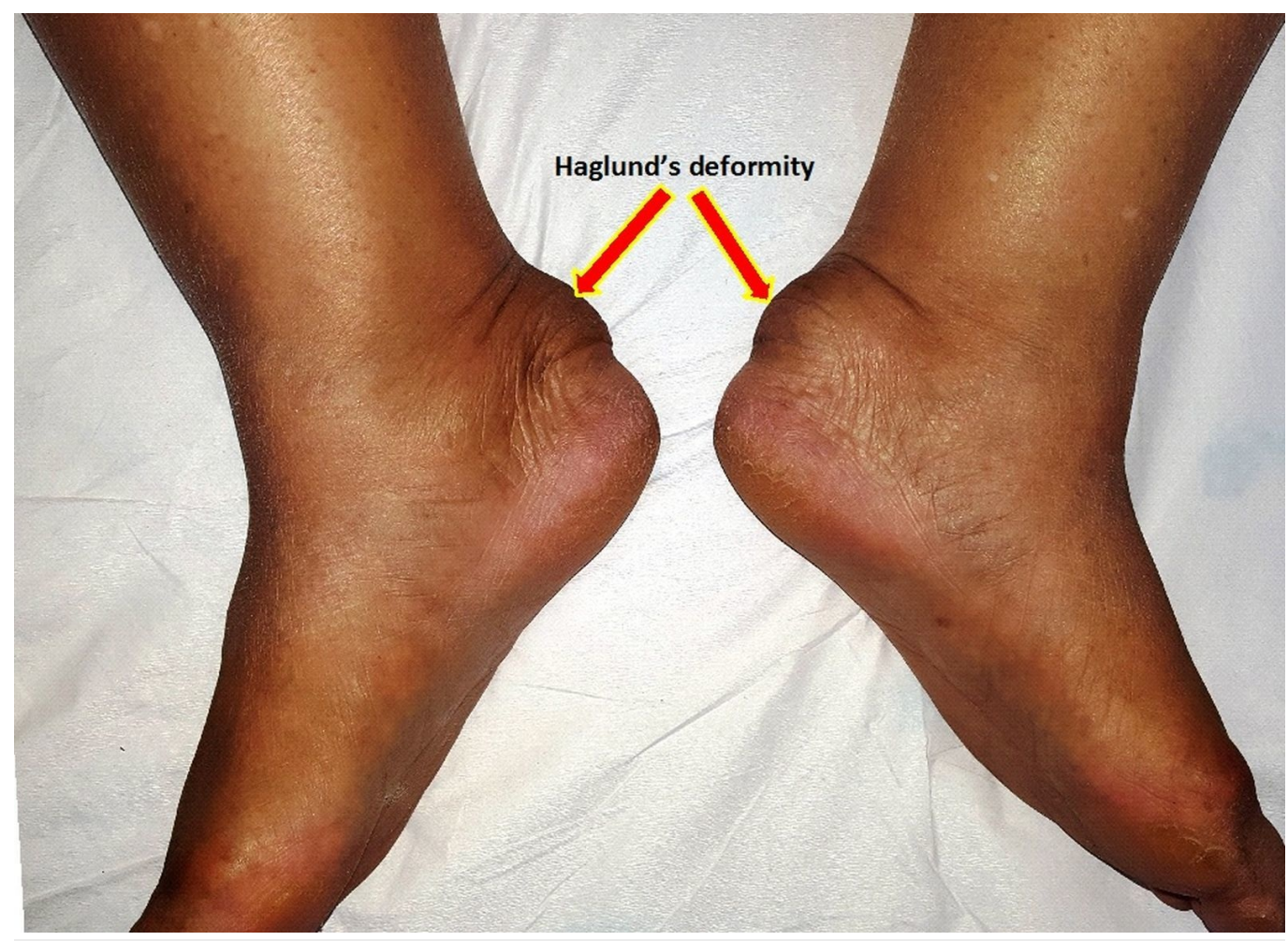

FIGURE 1: Clinical photograph of both ankles showing prominent swelling over the back of both heels

Signs of inflammation like swelling, warmth, redness, and tenderness may be present over the 


\section{Cureus}

posterior heel. If a careful physical examination is done, it may be possible to differentiate whether the inflammation is anterior to the Achilles tendon or posterior.

\section{Radiographic evaluation}

In a lateral radiograph, a bony prominence (Haglund's lesion) at the posterosuperior part of the calcaneal tuberosity, calcaneal bursal swelling, and increased density in pre-Achilles bursae (Figure 2) are apparent in these patients [6]. These findings may be associated with a calcaneal spur and heterotopic bone formation at the insertion of the Achilles tendon and within the Achilles tendon. The diagnosis of Haglund's syndrome is often based on history and clinical findings; radiographic changes may add a further clue to its diagnosis. There are no clear cut radiological criteria for diagnosing Haglund's lesion, especially in the early stages. However, some angles on plain radiographs have been described [7-8].

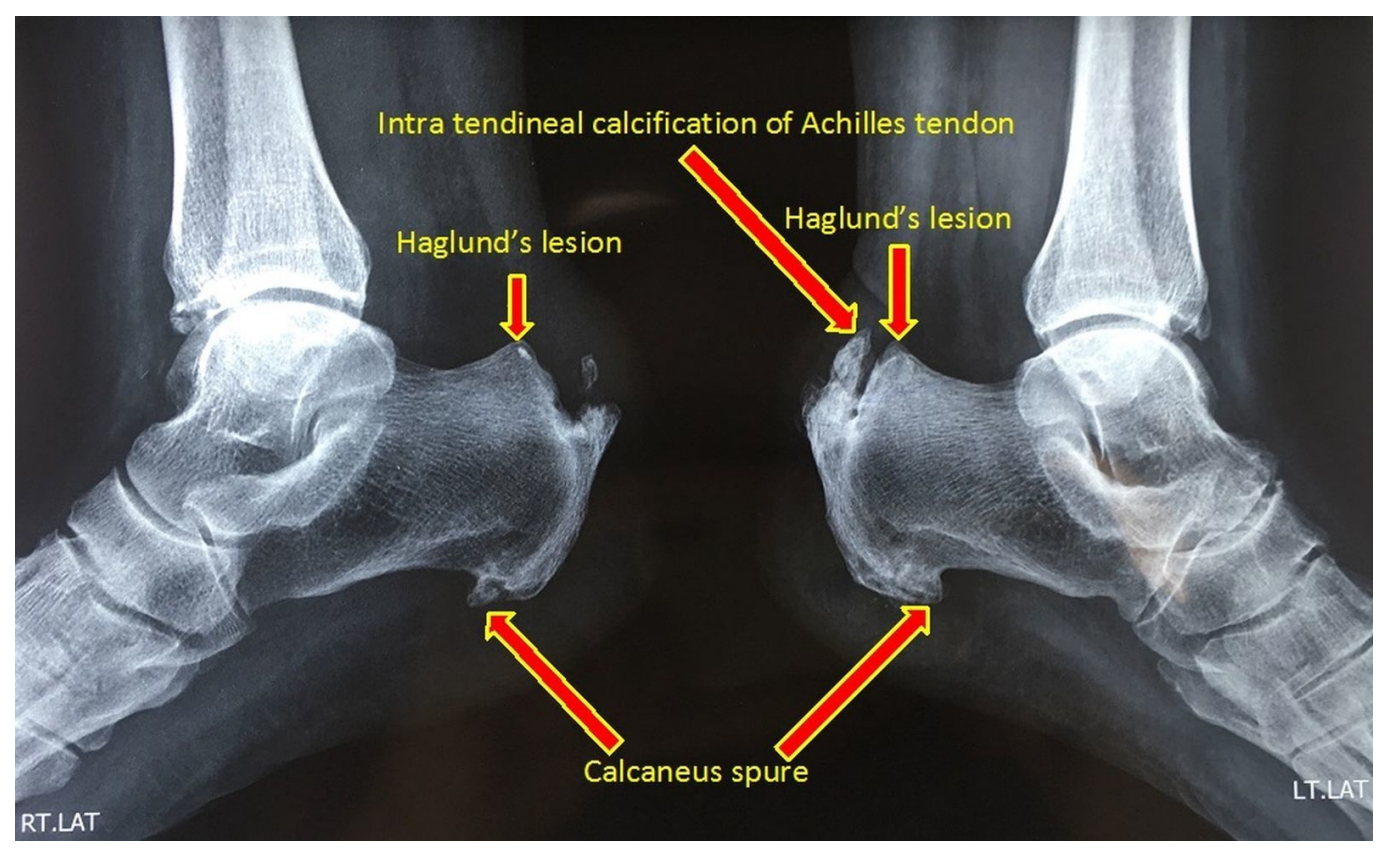

FIGURE 2: Lateral radiograph of ankles showing bony enlargement at the posterosuperior aspect of both calcaneum

A magnetic resonance imaging (MRI) scan is done in questionable cases. It shows posterosuperior calcaneal spurring with impingement on the Achilles tendon. There may be associated synovial thickening and collection in the retrocalcaneal bursa with thickening and high signal in the insertional fibers of Achilles tendon and edema in the adjoining retroAchilles fat pad (Figure 3). All these findings are consistent with Achilles tendinosis with retrocalcaneal and retro-Achilles bursitis [9]. 


\section{Cureus}

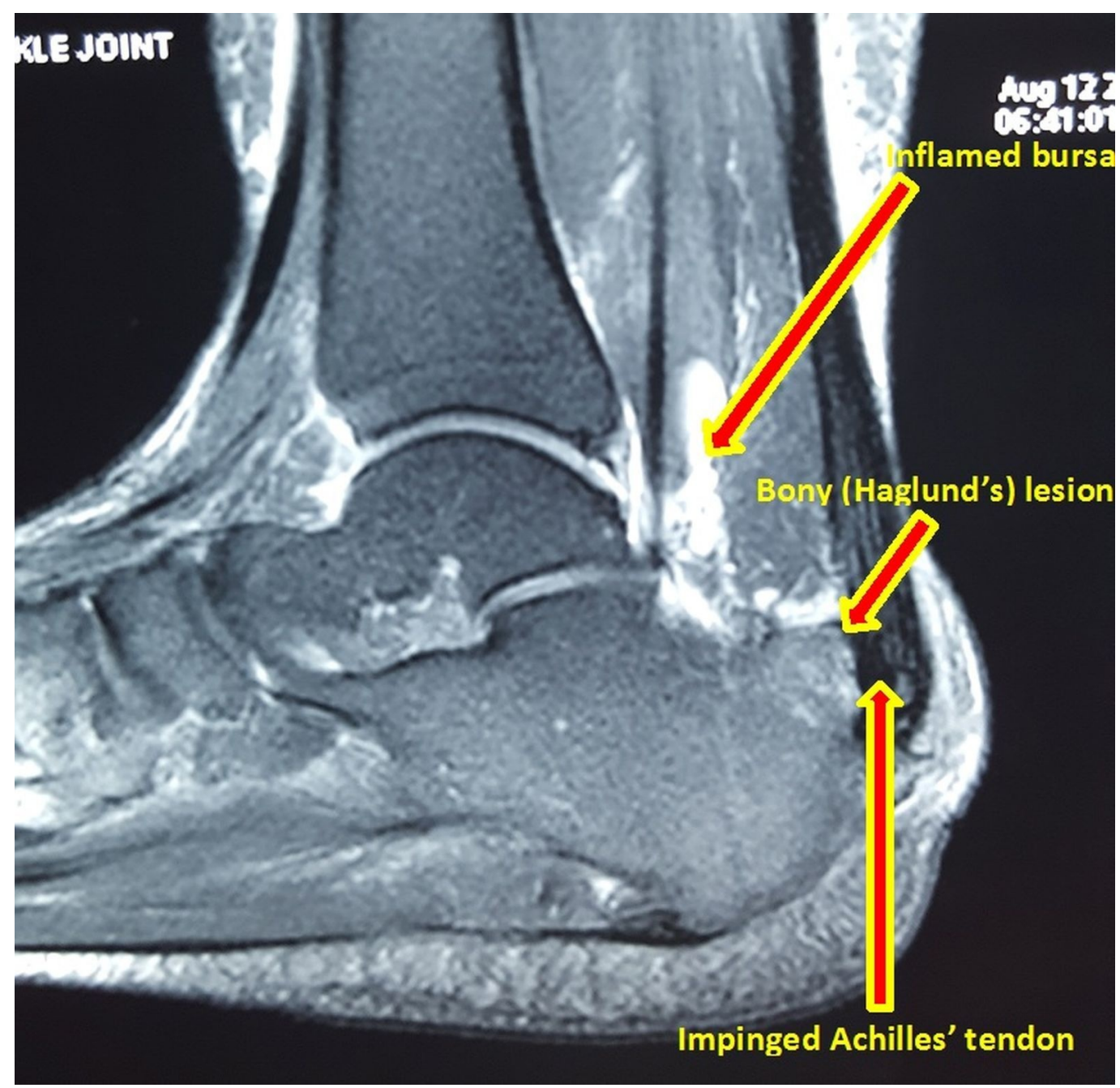

FIGURE 3: MRI image of ankle and foot showing posterosuperior bony spurring of calcaneus, retrocalcaneal bursitis, and impingement of Achilles tendon

\section{Differential diagnosis}

Detection of localized tenderness around the heel may help in differentiating this syndrome from mimicking conditions like isolated calcaneal bursitis, insertional Achilles tendinosis, plantar fasciitis, and avulsion of the calcaneal tendon (Table 1). 


\section{Cureus}

$\begin{array}{ll}\text { Conditions } & \text { Signs and symptoms } \\ \text { Calcaneal bursitis } & \text { Tenderness is mostly palpable on medial or lateral sides and in front of Achilles tendon. } \\ \text { Achilles tendinosis } & \text { Tenderness is present distally at the insertion of the Achilles tendon on the Calcaneus. } \\ \text { Planter fasciitis } & \text { Pain and tenderness is most commonly over the sole of the feet. } \\ \text { Avulsion of calcaneal tendon } & \text { A defect of gap is palpable in the tendon and Thompson test is positive. }\end{array}$

\section{TABLE 1: Distinguishing features of the conditions mimicking Haglund's syndrome}

\section{Treatment}

Conservative measures include a reassessment of the shoe of the patient and heel pads or heel lifts in the cases of high arched feet [10]. Casting may be necessary for pain reduction and an ice bag may be necessary to deal with swelling. Anti-inflammatory drugs (oral or topical), stretching exercises, and physiotherapy may relieve tension from the calcaneal tendon. Local perilesional steroid injections are also used in refractory cases [11].

If conservative treatment is not effective then surgical treatment options like retrocalcaneal decompression and calcaneal ostectomy or osteotomy are used [12]. Inadequate bone resection can lead to the recurrence of symptoms [13].

The surgical technique is as follows. After administration of general or regional anesthesia, a longitudinal lateral incision $1 \mathrm{~cm}$ lateral to the Achilles tendon is made, extending distally from 3-4 cm proximal to the superior tuberosity of the calcaneus to $2-3 \mathrm{~cm}$ distal to the superior tuberosity of the calcaneus. The ankle joint is plantar flexed, and by sharp and blunt dissection, the Achilles tendon is identified. A right-angled retractor is placed between the Achilles tendon and the posterior and superior borders of the calcaneal tuberosity. The retrocalcaneal bursa is exposed as well as the superior border of the calcaneal tuberosity without raising any of the Achilles tendon off the calcaneus (Figure 4).

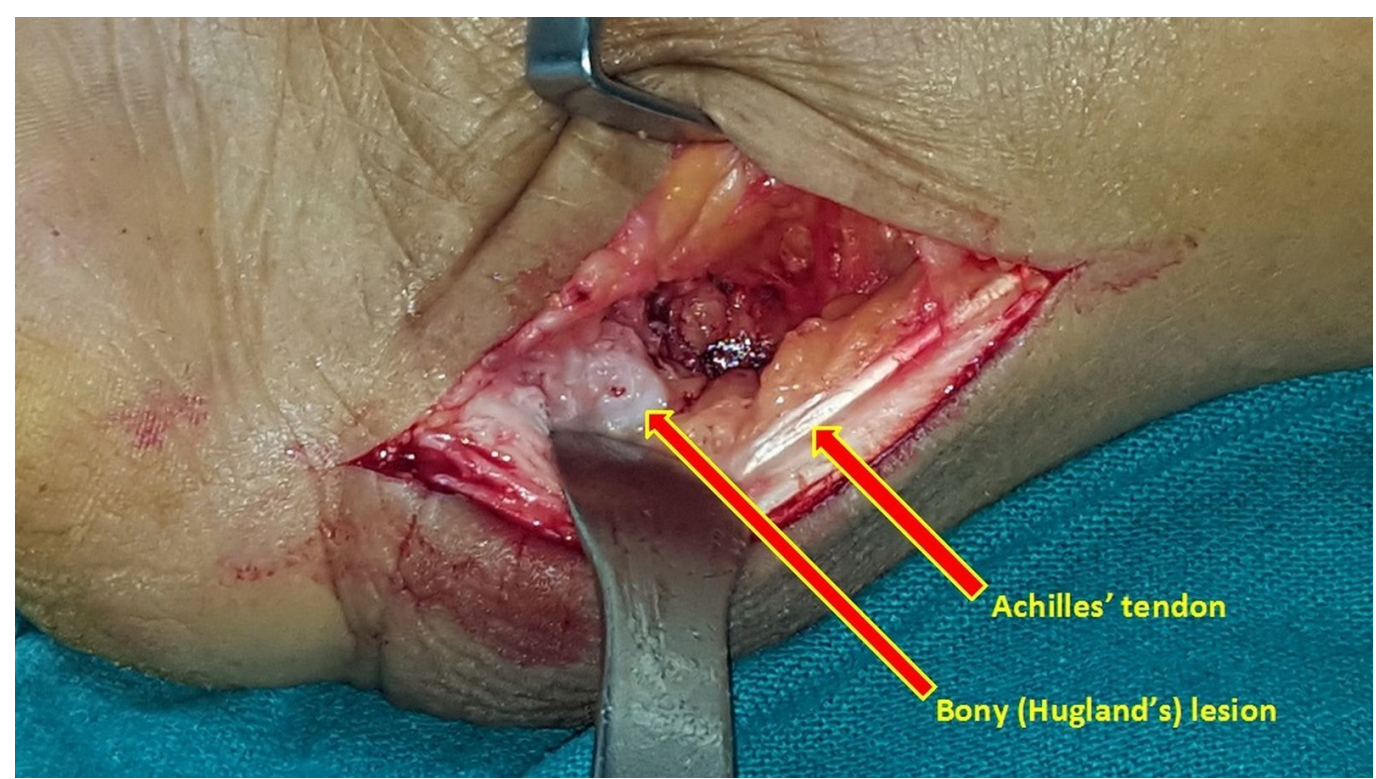




\section{Cureus}

\section{FIGURE 4: Intraoperative image of the bony lesion in Haglund's syndrome}

However, the Achilles tendon has such an extensive insertion into the posterior and plantar aspect of the calcaneal tuberosity that raising a 1-2 cm-long portion of the tendon may be necessary to resect the bone adequately. The retrocalcaneal bursa is removed first then the superior aspect of the tuberosity is removed with an osteotome (Figure 5). The placement of several drill holes along the proposed osteotomy site makes this resection easier. If intratendineal calcification is present, it should be removed. A well-padded, short leg, nonweight-bearing cast is applied, with the ankle in approximately 20 degrees of plantar flexion.

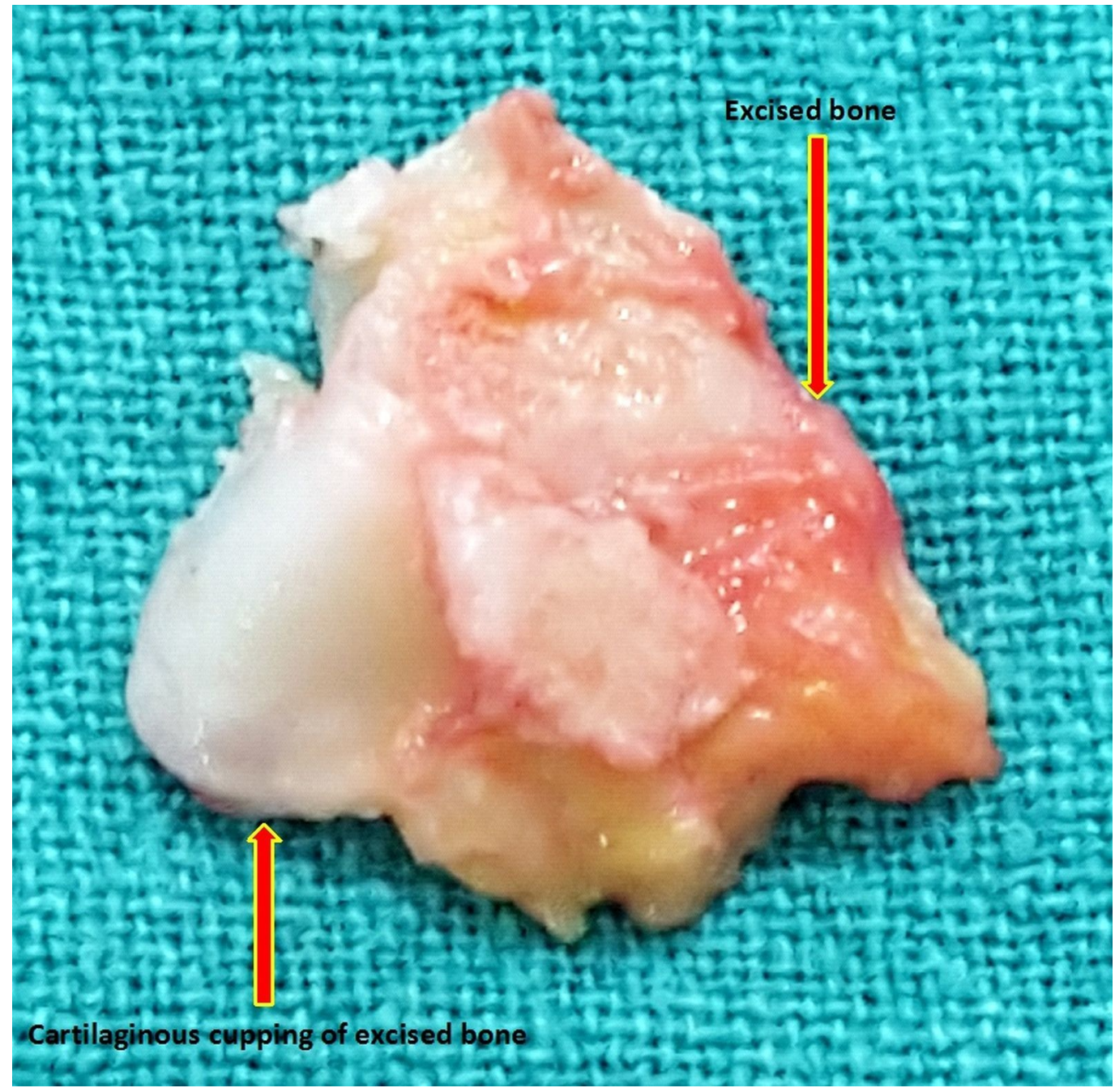

FIGURE 5: Excised bony (Haglund's) lesion

The cast and sutures are removed at two weeks, but the non-weight-bearing cast remains on for three weeks. Then a removable weight-bearing cast boot is applied, and active plantar flexion and dorsiflexion exercises are begun. It is important in the preoperative counseling to explain to a young woman with a pump bump that it might be three to six months before she can wear a stylish shoe and that there is no guarantee that she will ever be able to do so comfortably [14]. 
The reported surgical complications include Achilles tendon avulsion, persistent posterior heel pain, wound breakdown, nerve injuries (medial calcaneal sensory nerve and sural nerve), ankle stiffness, and incisional neuroma [15].

\section{Conclusions}

Haglund's syndrome is a common cause of hind foot pain in adults, but it is still a poorly understood clinical condition. Conservative management is often effective in most cases, and surgery is required only in resistant cases.

\section{Additional Information Disclosures}

Conflicts of interest: In compliance with the ICMJE uniform disclosure form, all authors declare the following: Payment/services info: All authors have declared that no financial support was received from any organization for the submitted work. Financial relationships: All authors have declared that they have no financial relationships at present or within the previous three years with any organizations that might have an interest in the submitted work. Other relationships: All authors have declared that there are no other relationships or activities that could appear to have influenced the submitted work.

\section{References}

1. Lawrence DA, Rolen MF, Morshed KA, et al.: MRI of heel pain. Am J Roentgenol. 2013, 200:845-855. 10.2214/AJR.12.8824

2. Jiménez Martín F, Alonso Valdazo MD, Díaz Peña G, Fernández Leroy J, Hernández Herrero D, Díaz García F: Haglund's syndrome. Two case reports. [Article in English, Spanish] . Rheumatol Clin. 2016, S1699-258X(16)00003-6. 10.1016/j.reuma.2015.12.006

3. Kucuksen S, Karahan AY, Erol K: Haglund syndrome with pump bump. Med Arch. 2012, 66:425-427.

4. Reule CA, Alt WW, Lohrer H, et al.: Spatial orientation of the subtalar joint axis is different in subjects with and without Achilles tendon disorders. Br J Sports Med. 2011, 45:1029-1034.

10.1136/bjsm.2010.080119

5. Aldridge T: Diagnosing heel pain in adults. Am Fam Physician. 2004, 70:332-338.

6. Pavlov H, Heneghan MA, Hersh A, et al.: The Haglund syndrome: initial and differential diagnosis. Radiology. 1982, 144:83-88. 10.1148/radiology.144.1.7089270

7. Lu CC, Cheng YM, Fu YC, et al.: Angle analysis of Haglund syndrome and its relationship with osseous variations and Achilles tendon calcification. Foot Ankle Int. 2007, 28:181-185. 10.3113/FAI.2007.0181

8. Singh R, Rohilla R, Siwach RC, et al.: Diagnosis significance of radiologic measurements in posterior heel pain. Foot. 2008, 18:91-98. 10.1016/j.foot.2008.01.005

9. Lawrence DA, Rolen MF, Morshed KA: MRI of heel pain. AJR Am J Roentgenol. 2013, 200:845855. 10.2214/AJR.12.8824

10. Stephens MM: Haglund's deformity and retrocalcaneal bursitis . Orthop Clin North Am. 1994, 25:41-46.

11. Sella EJ, Caminear DS, McLarney EA: Haglund's syndrome. J Foot Ankle Surg. 1998, 37:110114. 10.1016/S1067-2516(98)80089-6

12. Watson AD, Anderson RB, Davis WH: Comparison of results of retrocalcaneal decompression for retrocalcaneal bursitis and insertional Achilles tendinosis with calcific spur. Foot Ankle Int. 2000, 21:638-642.

13. Reinherz RP, Smith BA, Henning KE: Understanding the pathologic Haglund's deformity. J Foot Surg. 1990, 29:432-435.

14. Lohrer H, Nauck T: Results of operative treatment for recalcitrant retrocalcaneal bursitis and midportion Achilles tendinopathy in athletes. Arch Orthop Trauma Surg. 2014, 134:10731081. 10.1007/s00402-014-2030-8

15. Clain MR, Baxter DE: Achilles tendinitis. Foot Ankle. 1992, 13:482-487. 